\title{
Important considerations for effective gas sensors based on metal oxide nanoneedles films
}

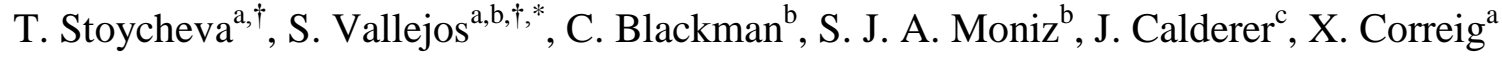 \\ ${ }^{a}$ Departament d'Enginyeria Electrònica, Universitat Rovira i Virgili, \\ Països Catalans 26, 43007 Tarragona, Spain \\ ${ }^{\mathrm{b}}$ Department of Chemistry, University College London \\ 20 Gordon Street, London, WC1H 0AJ, UK \\ ${ }^{c}$ Departament d'Enginyeria Electrònica, Universitat Politècnica de Catalunya, \\ Campus Nord 08034 Barcelona, Spain
}

\begin{abstract}
Gas sensor devices based on either polycrystalline or nanoneedle tungsten oxide were deposited in situ on classical ceramic substrates via AACVD, and subsequently functionalised with gold nanoparticles via sputtering. The sensing properties of the films were tested to a wide range of analytes, revealing high responses to ethanol, hydrogen, and nitrogen dioxide, at low operating temperatures $\left(\leq 250{ }^{\circ} \mathrm{C}\right)$, and a lack of response to carbon monoxide, ammonia, and hydrogen sulfide. In addition, the sensing responses to hydrogen and nitrogen dioxide, at $100{ }^{\circ} \mathrm{C}$ and $150{ }^{\circ} \mathrm{C}$, were improved by using gold functionalised structures. Modest differences of the sensor response magnitude in polycrystalline, and nanoneedle films were observed, suggesting the need of special substrate platforms for effective application of nanostructured films in gas sensors devices.
\end{abstract}

Keywords: Tungsten oxide, gas sensors, gold functionalised structures, CVD

$\dagger$ Joint first authors

*Corresponding author. Tel.: +44 2076797519; fax: +44 2076794703

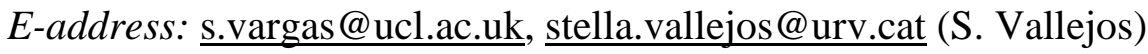




\section{Introduction}

Gas sensors are a crucial part of modern life with applications in environmental monitoring, domestic safety, public security, and food quality assessment amongst many others [1]. In particular, chemo-resistive sensors based on wide-bandgap semiconducting metal oxides (MOX), comprise a significant sector of the gas sensor market against a host of competing technologies, because of their low cost, high sensitivity, fast response, and relative simplicity. Much research into gas sensor optimisation has been focussed on decreasing the particle or grain size of polycrystalline MOX to the nanometre scale. In nanoparticles (NP) the surface states formed during gas adsorption effectively extend throughout the entire particle, which has been demonstrated to give a dramatic increase in gas sensitivity [1-3]. Sensitivity also depends on factors other than the crystallite size, such as the concentration of adsorption sites, the energy levels within the material, and the adsorption/desorption energies of interacting gas molecules, which are dependent on the shape, microstructure and crystallographic orientation of crystallite planes within the nanoparticle [4]. In this context nanostructured materials (NSM) such as nanowires (NW), nanobelts (NB), nanoribbons (NR), and nanoneedles (NN) may have an impact in all these factors, and enhance the performance of the sensing films, making NSM very attractive for gas sensor applications [5-7]. To date, three approaches for fabricating chemoresistive gas sensors based on NSM have been used [5]. The first deals with single structures (e.g. single NW) connected between metal electrodes. The second is based on the deposition of pre-grown NSM over a sensor substrate; many different methods have been used, including screen-printing and drop coating. The third, less common, approach involves growth of NSM directly on the sensor substrate (in situ techniques). The first approach is more expensive, and time consuming due to its complicated fabrication process, whilst the other two approaches are more suitable for mass production, and commercialization with the in situ approach having the advantage of fewer processing steps, hence the interest in establishing methods compatible with existing sensor technology for in situ fabrication.

Aerosol Assisted Chemical Vapour Deposition (AACVD) is a technique that allows the growth of polycrystalline or NSM via self-catalysed growth mechanism [8] at relatively low temperatures (e.g. $500{ }^{\circ} \mathrm{C}$ ). AACVD is a potentially scalable deposition method suitable for deposition of a variety of MOX for different applications [9], with both $\mathrm{NN}$ and spherical particles of $\mathrm{WO}_{3}$ having been produced [10, 11], as well as 
particles of $\mathrm{ZnO}$ [12], and $\mathrm{NN}$ and particles of $\mathrm{In}_{2} \mathrm{O}_{3}$ [13]. Hence AACVD provides a flexible route to produce high quality NSM of various materials for gas sensing applications.

Although, good sensitivities to analytes can be achieved in NSM based sensors, typical problems such as poor selectivity and stability are still present, which leads to many issues in real-world applications. Strategies based on the modulation of sensor temperature [14], during gas-solid interactions, and its optimization through different methods have been successfully applied to overcome this problematic [15-17]. However, from the material perspective the addition of catalyst or functionalization of the MOX (typically with noble metals) is widely studied to improve selectivity, reduce response time, and operating temperature $[1,3,18]$. A variety of methods are used for this purpose, with sputtering one of the simplest methods, which has been demonstrated to be effective when used for functionalising MOX [19]. Thus, in this work tungsten oxide NN grown via AACVD were functionalised with gold NP via sputtering.

Herein, we report the development of polycrystalline, NN, and Au-functionalised NN tungsten oxide based gas sensors, and their characterization to a wide range of analytes. The gas sensors were fabricated on classical ceramic substrates to evaluate the potential application of NSM in commercial gas sensor devices.

\section{Experimental}

\subsection{AACVD set-up}

A piezoelectric ultrasonic atomiser (frequency $\sim 1.5 \mathrm{MHz}$ ) was used to generate an aerosol from a precursor solution $(6.7 \mathrm{mM})$ of $\left[\mathrm{W}(\mathrm{OPh})_{6}\right]$ (synthesised according to the literature [20]) dissolved in various solvents. The aerosol droplets were transported by a nitrogen gas flow $(0.5 \mathrm{l} / \mathrm{min})$ to the heated substrate placed in a self-made cold-wall CVD reactor. Under these conditions the time taken to transport the entire volume of the solution $(30 \mathrm{ml})$, i.e. the deposition time, was typically 30 and 100 minutes, depending on the solvent used. The CVD reactor consisted of two cylindrical pieces (diameter: $95 \mathrm{~mm}$, height: $40 \mathrm{~mm}$ ) made from stainless steel. The first one was used as the reactor base, and contained two cartridge heaters (power density: $23.54 \mathrm{~W} / \mathrm{cm}^{3}$ ) and a Pt-Rh thermocouple; both elements were placed close to the substrate, which rested at the top of the reactor base. The second piece was used as a top plate, and was positioned parallel to the substrate 
and $7 \mathrm{~mm}$ above it. The reactor inlet was positioned horizontally, and the exhaust vertically to the substrate, both across the reactor base (Figure 1).

\subsection{Tungsten oxide deposition}

Tungsten oxide nanostructures were deposited via AACVD on $10 \mathrm{~mm} \times 10 \mathrm{~mm} \times$ $0.64 \mathrm{~mm}$ alumina $\left(\mathrm{Al}_{2} \mathrm{O}_{3}\right)$ tiles (Figure 1, inset) with inter-digitated Pt electrodes (gap: $300 \mu \mathrm{m}$, thickness: $9 \mu \mathrm{m}$ ) on the surface, and a Pt heater on the reverse side. The design and fabrication of the sensor substrate was previously reported in reference [21]. Several deposition temperatures, between $300^{\circ} \mathrm{C}$ and $550{ }^{\circ} \mathrm{C}$, and different solvents (acetone, toluene or 50:50 mixture of acetone and toluene) were studied in order to find the optimal condition for the deposition of polycrystalline (particles) and NN films. The morphology of the as-deposited, and annealed $\left(500{ }^{\circ} \mathrm{C}-2 \mathrm{~h}\right)$ films was examined using Environmental Scanning Electron Microscopy (ESEM - FEI Quanta 600, $20 \mathrm{keV}$ ) and Transmission Electron Microscopy (TEM - JEOL 1011, $100 \mathrm{keV}$ ). The structural properties of the films were analysed using X-ray Diffraction (XRD - Bruker AXS D8-Discover, 40 kV, 40 mA, $\mathrm{Cu} \mathrm{K}<$ alpha $>$ radiation). Diffraction patterns were recorded from $15^{\circ}$ to $70^{\circ}$ 2theta. Identification of the crystal phases was achieved by comparison of the patterns with the ICDD database using Diffract ${ }^{\text {plus }}$ Evaluation software, and the mean crystallite size and crystal orientation were analyzed using the TOPAS 3.1 program.

\subsection{Gold functionalised tungsten oxide}

Tungsten oxide NN were functionalised with gold NP deposited by r.f. magnetron sputtering (ESM100 Edwards sputtering system). The sputtering conditions were chosen in order to avoid the coalescence of gold NP, and the formation of a continuous film on the tungsten oxide nanostructure, thus the r.f. sputtering power was adjusted to $10 \mathrm{~W}$, and the sputtering time to $3 \mathrm{~min}$. A gold target of $99.99 \%$ purity was used in an atmosphere consisting of Ar, and the flow rate was maintained at $10 \mathrm{sccm}$ by a gas flow meter. The pressure in the deposition chamber during sputtering was $5 \times 10^{-3}$ mbar.

\subsection{Gas sensing characterization}

Gas sensing characterization was carried out by monitoring the resistance change of the non-functionalised and functionalised films during exposure to different concentrations of gas in a continuous flow test chamber (chamber volume: $280 \mathrm{~cm}^{3}$ ) [22]. 
Several sensor-operating temperatures in the range of $100-300{ }^{\circ} \mathrm{C}$ were tested. In order to obtain the desired concentration, calibrated cylinders of ethanol $(\mathrm{EtOH})$, hydrogen $\left(\mathrm{H}_{2}\right)$, carbon monoxide $(\mathrm{CO})$, ammonia $\left(\mathrm{NH}_{3}\right)$, hydrogen sulfide $\left(\mathrm{H}_{2} \mathrm{~S}\right)$, and nitrogen dioxide $\left(\mathrm{NO}_{2}\right)$, all in synthetic air, were mixed with pure synthetic air. A summary of the gas concentrations tested is presented in Table 1. The sensors were exposed to the analyte gas for 10 minutes, and subsequently the chamber was purged with air until the initial baseline resistance was recovered. In order to determine the repeatability 5 replications were carried out for each gas and operating temperature tested. The sensor response was defined as $S=R_{\text {gas }} / R_{\text {air }}$ both for an increase or decrease of sensor resistance. $R_{\text {air }}$ represents the sensor resistance in air at stationary state and $\mathrm{R}_{\mathrm{gas}}$ is the sensor resistance after 10 minutes of gas exposure. The response time was defined as the time required for the sensor to reach $90 \%$ of the sensor response, and the recovery time as the time required to reach $10 \%$ of the initial baseline resistance after the analyte was purged.

\section{Results and discussion}

\subsection{Film analysis}

Figure 2 displays the film morphology observed according to the deposition temperatures, and 'carrier' solvent used for AACVD. SEM images of the films show that the deposition temperature is a determining parameter in the formation of nanostructures, i.e. NN, whereas the 'carrier' solvent suggests an influence on the temperature at which nanostructures are formed in preference to dense polycrystalline (particle) films. Thus acetone-only solution formed particles at $450{ }^{\circ} \mathrm{C}$ and flower-like $\mathrm{NN}$ structures at $550{ }^{\circ} \mathrm{C}$ (Figure 2a). Similarly, toluene-only solution formed particles at $450{ }^{\circ} \mathrm{C}$ and non-aligned $\mathrm{NN}$ agglomerations at $500{ }^{\circ} \mathrm{C}$, and $550^{\circ} \mathrm{C}$ (Figure 2b), whereas acetone/toluene (50:50) solution displayed particles at $350{ }^{\circ} \mathrm{C}$ and high density of mat-like $\mathrm{NN}$ at $500{ }^{\circ} \mathrm{C}$ (Figure 2c). In all cases the intermediate deposition temperatures $\left(500{ }^{\circ} \mathrm{C}\right.$ for acetone-only and toluene-only and $400-450{ }^{\circ} \mathrm{C}$ for acetone/toluene mixture) showed a halfway between particles, and NN morphology, suggesting the nucleation and subsequent growth of NN structures occurs after an initial polycrystalline film is accumulated on the substrate, which is in agreement with the self-catalysed growth mechanism proposed previously [23]. The influence of solvent on the morphology of AACVD tungsten oxide films was recently considered in detail in reference [8]. Similar non-aligned and mat-like tungsten 
oxide NN, growth by self-catalysed direct vapour-solid mechanism, have been reported previously [11, 24], as well as other nanostructures such as tube-like [25], rod-like [26], or flake-like [27]. According to reference [24], NN mat-like morphologies are effective structural arrangements for gas sensing applications, which suggests that NN films deposited at $500{ }^{\circ} \mathrm{C}$ from an acetone/toluene mixture (Figure 2c) are attractive for gas sensor fabrication. In this context, polycrystalline and NN films were fabricated using acetone/toluene mixture, at $350{ }^{\circ} \mathrm{C}$ and $500{ }^{\circ} \mathrm{C}$. This deposition conditions yielded high quality films and uniform coverage of the sensor substrate and electrodes.

Cross section imaging of the non-functionalised films revealed the thickness of the polycrystalline layer to be $\sim 900 \mathrm{~nm}$ (Figure 3a) and the length of the NN to be $\sim 10 \mu \mathrm{m}$ (Figure 3b). TEM of the NN films (Figure 4), previously removed from the substrate by sonication in methanol, showed that the NN diameters vary between $50 \mathrm{~nm}$ and $100 \mathrm{~nm}$. In addition ESEM and EDS analysis of the NN films after gold functionalization revealed gold clusters dispersed on the film surface, and TEM showed the presence of gold NP $(\sim 5 \mathrm{~nm})$ dispersed along the surface of the NN structure (Figure $4 \mathrm{~b}$ ), in contrast to nonfunctionalised samples (Figure 4a). Nevertheless, an even distribution of gold NP on each NN cannot be assured by using sputtering technique.

XRD of the polycrystalline and NN sensing active films showed the presence of a monoclinic phase described with the $\mathrm{P} 2{ }_{1} / \mathrm{n}$ space group, ICDD card no. 72-0677, $\mathrm{a}=$ $7.30600 \AA, \mathrm{b}=7.54000 \AA, \mathrm{c}=7.69200 \AA$, and beta $=90.88^{\circ}$, previously reported for tungsten oxide structures grown by AACVD $[11,28]$. Figure 5 displays the XRD patterns of the polycrystalline film, $a=7.3300(21) \AA, b=7.5421(26) \AA, c=7.67244(97) \AA$, and beta $=90.650(31)^{\circ}$, and NN film, $a=7.3300(39) \AA, b=7.5359(25) \AA, c=7.67509(73) \AA$, and beta $=90.703(29)^{\circ}$. The crystallite size, according to Scherrer equation, was estimated to be about $38.83(1.38) \mathrm{nm}$ in the polycrystalline films and $41.58(1.81) \mathrm{nm}$ in the $\mathrm{NN}$ composed films (numbers in brackets, for the crystallite size, represent the estimated standard deviation). The preferred orientation in both samples was determined as a combination of two directions [001] and [100] with different degrees of contribution, revealing less preferred orientation in polycrystalline films compared to $\mathrm{NN}$ based film. Note that the intensity of diffraction from the (200) plane is more defined for polycrystalline films. Similar patterns were observed after heating the films at $500{ }^{\circ} \mathrm{C}$ for $2 \mathrm{~h}$, indicating that the structures were unchanged after annealing process.

\subsection{Gas sensing characterization}


Gas sensors based on polycrystalline, $\mathrm{NN}$, and $\mathrm{Au} / \mathrm{NN}$ films were tested to different reducing and oxidizing analytes. Figure 6, 7, and 8 show the highest sensor responses, obtained over five measured responses, at each operating temperature. None of the films displayed responses to $\mathrm{NH}_{3}, \mathrm{CO}$, and $\mathrm{H}_{2} \mathrm{~S}$, hence only test results to EtOH, $\mathrm{H}_{2}$, and $\mathrm{NO}_{2}$ are shown in this section. The mean values and standard errors for each type of sensor, that displayed a response to the tested analyte, were comprised between \pm 0.3498 and \pm 2.620 , and are represented in Figure 9 .

\subsubsection{Sensitivity}

Gas sensing characterization of the structures to 'reducing analytes' revealed responses to $\mathrm{EtOH}$ and $\mathrm{H}_{2}$ (Figure 6, and 7). The highest sensor responses were displayed at $250{ }^{\circ} \mathrm{C}$ and $300{ }^{\circ} \mathrm{C}$, for $1.5 \mathrm{ppm}$ and $20 \mathrm{ppm}$ of $\mathrm{EtOH}$, respectively (Figure 6b), and at $150{ }^{\circ} \mathrm{C}$, for $1000 \mathrm{ppm}$ of $\mathrm{H}_{2}$ (Figure $7 \mathrm{~b}$ ). Unusual electrical resistance changes were observed according to EtOH concentration, sensor operating temperature, and film morphology (Figure 6a). For instance, $\mathrm{NN}$ and $\mathrm{Au} / \mathrm{NN}$ films displayed an increase of resistance to $1.5 \mathrm{ppm}$ of $\mathrm{EtOH}$, and an increase (at $100{ }^{\circ} \mathrm{C}$ ) or decrease (at $200{ }^{\circ} \mathrm{C}$ and 300 ${ }^{\circ} \mathrm{C}$ ) of resistance to $20 \mathrm{ppm}$ of $\mathrm{EtOH}$. In contrast, polycrystalline films displayed no response to $1.5 \mathrm{ppm}$ of $\mathrm{EtOH}$, and a slight increase of resistance (at $100{ }^{\circ} \mathrm{C}$ ) accompanied by a decrease of resistance (at $200{ }^{\circ} \mathrm{C}$ and $300{ }^{\circ} \mathrm{C}$ ) to $20 \mathrm{ppm}$ of EtOH. Similarly, hydrogen tests (Figure 7a) displayed an increase in film resistance regardless the film morphology except for Au-NN films, which showed a resistance decrease at $300{ }^{\circ} \mathrm{C}$. Moreover, testing of the films to $\mathrm{NO}_{2}$ showed an increase in electrical resistance of the film after exposition to this 'oxidizing analyte' (Figure 8b), demonstrating a typical n-type semiconductor behaviour, and a good sensitivity to $\mathrm{NO}_{2}$, as typically observed for tungsten oxide sensing films $[22,29]$. The highest sensor responses to $\mathrm{NO}_{2}$ were displayed at $150{ }^{\circ} \mathrm{C}$ either for polycrystalline, $\mathrm{NN}$ or $\mathrm{Au} / \mathrm{NN}$ films (Figure 8a).

Our results show that greater responses to each analyte are obtained at low temperatures $\left(\leq 250^{\circ} \mathrm{C}\right)$, whereas other works report the highest responses at more elevated temperatures (e.g. $400{ }^{\circ} \mathrm{C}$ both to $\mathrm{EtOH}[30]$ and $\mathrm{NO}_{2}$ [31], and $300^{\circ} \mathrm{C}$ to $\mathrm{H}_{2}$ [26]). As a result, longer response and recovery times were associated to our films (See Table 2). We also observed that the order of the sensor response magnitude, to the same analytes and concentrations, is comparable to other works [21, 22, 30, 31], which suggest a good agreement of our results with those in the literature. 


\subsubsection{Selectivity}

Polycrystalline, $\mathrm{NN}$ and $\mathrm{Au} / \mathrm{NN}$ sensing films showed a lack of response to $\mathrm{NH}_{3}$, $\mathrm{CO}$, and $\mathrm{H}_{2} \mathrm{~S}$, contrary to EtOH (Figure 6), $\mathrm{H}_{2}$ (Figure 7), and $\mathrm{NO}_{2}$ (Figure 8), similar selective behaviour to these analytes was previously observed for tungsten oxide films $[22,31]$. The sensor response comparison displayed in Figure 9 indicate that the selectivity may be controlled by the addition of metal NP and the sensor operating temperature rather than the morphology of the film. In fact, the response of gold functionalised NN (Figure 9c) suggest that EtOH could be detected selectively at $250{ }^{\circ} \mathrm{C}$ and $\mathrm{NO}_{2}$ at $100{ }^{\circ} \mathrm{C}$, as well as a low cross sensitivity between $\mathrm{H}_{2}$ and $\mathrm{NO}_{2}$ at $150{ }^{\circ} \mathrm{C}$. In contrast, non-functionalised NN (Figure 9b) show poor selectivity at 100,250 , and $300{ }^{\circ} \mathrm{C}$ and low cross sensitivities at $150{ }^{\circ} \mathrm{C}$ and $200{ }^{\circ} \mathrm{C}$. In the case of polycrystalline films (Figure 9a), we observed high cross sensitivities for all operating temperatures, indicating a poor selectivity of these films to the tested analytes.

\subsubsection{Stability}

The gas sensors fabricated for this work were tested over a period of $480 \mathrm{~h}$, being exposed to several contaminant gases $\left(\mathrm{EtOH}, \mathrm{H}_{2}, \mathrm{NO}_{2}, \mathrm{NH}_{3}, \mathrm{CO}\right.$, and $\left.\mathrm{H}_{2} \mathrm{~S}\right)$ at temperatures between $100{ }^{\circ} \mathrm{C}$ and $300{ }^{\circ} \mathrm{C}$. After the gas sensing experiments ESEM and XRD was carried out on the films, showing the morphology and structure was unchanged in the films. Moreover, the baseline resistance recorded for the films at each sensoroperating temperature showed slight changes during the testing period, which were comprised between 1.2-1.4 M $\Omega$ for polycrystalline films, 2.3-2.4 M $\Omega$ for NN films, and 1.1-1.4 $\mathrm{M} \Omega$ for $\mathrm{Au} / \mathrm{NN}$ films. These results suggest a good stability of the sensing active films over the testing period.

\subsection{Discussion}

The results from gas sensing characterization show that the films are sensitive to EtOH, $\mathrm{H}_{2}$, and $\mathrm{NO}_{2}$. The magnitude of the sensor response is dependent on sensoroperating temperature, and whether polycrystalline or $\mathrm{NN}$ films are used as sensing films. Thus, NN films had greater responses to $\mathrm{EtOH}$, and $\mathrm{H}_{2}$ (Figure 6a, 7a), whereas polycrystalline films showed greater responses to $\mathrm{NO}_{2}$ (Figure 8).

In chemo-resistive gas sensors, many complex factors affect the magnitude of the sensor response. In particular, it is accepted that the overall response is a contribution of the receptor function, transducer function, and utility factor (i.e. capability of diffusion 
and reaction of the analytes through the structure) of the sensing film; these factors being film morphology and/or crystalline structure dependant. The NN sensing films tested in our experiments are expected to have enhanced receptor function and utility factor due to the higher density of surface defects of NN films [28], and their particular nanostructured morphology compared to polycrystalline films. However, the differences in response observed between NN and polycrystalline films were not significant. For instance tests to EtOH, and $\mathrm{H}_{2}$ (Figure 6,7) suggest that $\mathrm{NN}$ films have slightly better sensor response, compared to polycrystalline films, except at $300{ }^{\circ} \mathrm{C}$, where polycrystalline films showed better response. In contrast, tests for $\mathrm{NO}_{2}$ revealed polycrystalline films have greater sensor responses compared to NN films (Figure 8). These contradictory, and modest differences between polycrystalline and NN films suggest a low contribution of the transducer function in $\mathrm{NN}$ films to the overall sensor response (i.e. how the response of each NN is transformed into that of the whole device). The high orientation of the crystals in the $\mathrm{NN}$ bulk favours the electron transport, and therefore the transducer function of individual NN. However, and contrary to single NN sensors, the electron transport in NN films also depends on the NN/NN boundary as previously reported [24]. Although, in our experiments we have chosen mat-like films to enhance the NN/NN boundary in the film, it is apparent that the electrode configuration (with wide gaps typically used for polycrystalline films) does not improve the interconnected networked NN mats, indicating the need of special electrodes configuration - with electrode gaps similar to the NN length as suggested in reference [32] - that effectively interconnect the NN in the film, improving the sensor response, and possibly the response and recovery time of the NN based gas sensors. In addition, short gap electrodes are also expected to control the density of NN/NN boundaries between contacts, contributing positively to the sensor response [33], analogously to the inter-grain boundary in polycrystalline films [34]. In this context the application of nanostructured films, instead of polycrystalline films, in commercial gas sensor platforms seems in question, and the development of new substrate platforms that attain effective application of these structures in gas sensor devices will be essential.

The gas sensing results of the functionalised NN films indicate gold NP enhance the sensor response of $\mathrm{NN}$ films to $\mathrm{H}_{2}$ (Figure 7a) and $\mathrm{NO}_{2}$ (Figure 8) at low operating temperatures, below $150{ }^{\circ} \mathrm{C}$, as well as to $1.5 \mathrm{ppm}$ of EtOH at $250{ }^{\circ} \mathrm{C}$ (Figure 6a), which suggest gold NP catalyse $\mathrm{O}_{2}$ and $\mathrm{H}_{2}$ dissociation on its surface, leading to an enhancement on the receptor function of tungsten oxide, and therefore on the magnitude of the sensor response. These observations are in agreement with other reports, in which it was stated an 
improvement of polycrystalline tungsten oxide sensing properties to $\mathrm{NO}_{2}, \mathrm{H}_{2}$, and EtOH by functionalization of the structure with gold NP [26, 28, 29]. The response and recovery times recorded for the highest sensor responses to $\mathrm{EtOH}, \mathrm{H}_{2}$, and $\mathrm{NO}_{2}$ (Table 2) shows that there is an improvement of the response time scales in Au functionalised NN films compared to non-functionalised films. These results suggest that the activation energy needed to induce surface combustion of the analyte at the $\mathrm{Au} / \mathrm{NN}$ surface is reduced by the gold functionalization, as establish in the literature [35]. It is important to mention that the catalytic activity of Au NP on metal oxides depends strongly on the size, shape and distribution of the metal NP along the surface [36], and therefore the enhancement of the sensor response magnitude by using metal NP depends on the method used for functionalization. For instance, we observed previously that co-deposition of tungsten oxide NN and gold NP via AACVD, has a stronger effect in sensitivity to $1.5 \mathrm{ppm}$ of EtOH compared to films functionalised by sputtering [28].

The unusual electrical resistance changes of the films to reducing gases indicate a transition from n- to p-type conduction, assigned to the formation of an inversion layer [37], which was also reported for $\mathrm{WO}_{3}$ nanorod [38] and $\mathrm{TeO}_{2}$ nanowires [39] based gas sensors upon exposure to EtOH. In fact, this effect is most likely to be presented in NSM, compared to bulk materials, due to the comparable dimensions between the mean free path of the carriers, and the diameter, and/or thickness of the NSM. The formation of an inversion layer and the changes in the conduction type of the sensing film could be induced either by certain kinds of reductive ambient, the use of additives on the surface or different surface reactions under different conditions, for instance humidity and temperature. In the case of $\mathrm{EtOH}$, the formation of an inversion layer is related to the fact that the reaction mechanism of EtOH at the MOX surface may belong to a class of acceptor or donor reaction [40]. In our tests we believe that an acceptor type reaction occurs at low EtOH concentrations, showing resistance changes only in the NN based films due to a higher surface-to-volume ratio, and a better utility factor of these structures compared to particle based films. In contrast at high concentrations a donor type reaction occurs, showing a typical decrease of the film resistance both in $\mathrm{NN}$ and polycrystalline films. In the case of hydrogen, the formation of an inversion layer could be linked with a more complex phenomena probably related to the rates of the adsorption and recombination of hydrogen at the tungsten oxide surface [40], however in this work we cannot provide direct evidence to support this suggestion. These particular changes in the 
conduction type of NSM could be used to favour the selective detection of reducing analytes in certain applications.

\section{Conclusions}

Optimum deposition conditions to grow polycrystalline and NN mat-like morphology tungsten oxide films via AACVD using $\left[\mathrm{W}(\mathrm{OPh})_{6}\right]$ as a precursor were determined, and then used to deposit sensing active films in situ on classical gas sensor ceramic substrates. In addition, tungsten oxide NN films were functionalised, with gold NP via sputtering, preventing the formation of a continuous film. The gas sensing properties of polycrystalline, $\mathrm{NN}$ and $\mathrm{Au} / \mathrm{NN}$ films were studied by measuring the electrical resistance changes of the films during exposition to various analytes. In general, the sensors tested in this work revealed low optimum operating temperatures $\left(\leq 250{ }^{\circ} \mathrm{C}\right)$, and greater sensor responses to ethanol, hydrogen, and nitrogen dioxide with gold functionalised $\mathrm{NN}$ having shown an enhancement in sensitivity to these gases. Comparison of the sensing results of polycrystalline and $\mathrm{NN}$ based sensors revealed modest differences in the response magnitude, bringing into consideration the need of special substrate platforms for competitive application of nanostructured films in chemoresistive gas sensors. Therefore, further research on the ideal sensor substrate arrangement, for NN sensing films, is in process.

\section{Acknowledgments}

This work has been funded in part by CICYT under project $N^{\circ}$ TEC2009-07107 SV and CB are grateful for the support of the Leverhulme Trust via Research Project Grant F/07 134/DB. 


\section{References}

[1] N. Yamazoe, Toward innovations of gas sensor technology, Sens. Actuator B-Chem., 108 (2005) 2-14.

[2] N. Barsan, U. Weimar, Conduction model of metal oxide gas sensors, J. Electroceram. , 7 (2001) 143-167.

[3] M.E. Franke, T.J. Koplin, U. Simon, Metal and metal oxide nanoparticles in chemiresistors: Does the nanoscale matter?, Small, 2 (2006) 36-50.

[4] A. Gurlo, Nanosensors: Does crystal shape matter?, Small, 6 (2010) 2077-2079.

[5] J. Huang, Q. Wan, Gas sensors based on semiconducting metal oxide one-dimensional nanostructures, Sensors, 9 (2009) 9903-9924.

[6] E. Comini, C. Baratto, G. Faglia, M. Ferroni, A. Vomiero, G. Sberveglieri, Quasi-one dimensional metal oxide semiconductors: Preparation, characterization and application as chemical sensors, Prog. Mater. Sci., 54 (2009) 1-67.

[7] N.S. Ramgir, Y. Yang, M. Zacharias, Nanowire-based sensors, Small, 6 (2010) 17051722.

[8] S. Vallejos, P. Umek, B. Blackman, AACVD Control parameters for selective deposition of tungsten oxide nanostrucutres, J. Nanosci. Nanotechnol., in press (2011). [9] X.H. Hou, K.L. Choy, Processing and applications of aerosol-assisted chemical vapor deposition, Chem. Vap. Deposition, 12 (2006) 583-596.

[10] C.S. Blackman, X. Correig, V. Khatko, A. Mozalev, I.P. Parkin, R. Alcubilla, T.

Trifonov, Templated growth of tungsten oxide micro/nanostructures using aerosol assisted chemical vapour deposition, Mater. Lett. , 62 (2008) 4582-4584.

[11] S. Ashraf, C.S. Blackman, R.G. Palgrave, S.C. Naisbitt, I.P. Parkin, Aerosol assisted chemical vapour deposition of $\mathrm{WO}_{3}$ thin films from tungsten hexacarbonyl and their gas sensing properties, J. Mater. Chem., 17 (2007) 3708-3713.

[12] G. Walters, I.P. Parkin, Aerosol assisted chemical vapour deposition of $\mathrm{ZnO}$ films on glass with noble metal and p-type dopants; use of dopants to influence preferred orientation, Appl. Surf. Sci., 255 (2009) 6555-6560.

[13] S. Basharat, C.J. Carmalt, S.A. Barnett, D.A. Tocher, H.O. Davies, Aerosol assisted chemical vapor deposition of $\operatorname{In}_{2} \mathrm{O}_{3}$ films from $\mathrm{Me}_{3} \mathrm{In}$ and donor functionalized alcohols, Inorg. Chem. , 46 (2007) 9473-9480.

[14] W.M. Sears, K. Colbow, F. Consadori, General characteristics of thermally cycled tin oxide gas sensors, Semicond. Sci. Technol., 4 (1989) 351-359. 
[15] S. Semancik, R.E. Cavicchi, M.C. Wheeler, J.E. Tiffanya, G.E. Poiriera, R.M. Walton, J.S. Suehle, B. Panchapakesan, D.L. DeVoe, Microhotplate platforms for chemical sensor research, Sens. Actuator B-Chem., 77 (2001) 579-591.

[16] A. Vergara, E. Llobet, J. Brezmes, P. Ivanov, C. Cané, I. Gràcia, X. Vilanova, X. Correig, Quantitative gas mixture analysis using temperature-modulated micro-hotplate gas sensors: Selection and validation of the optimal modulating frequencies, Sens. Actuator B-Chem., 123 (2006) 1002-1016.

[17] A. Vergara, M.K. Muezzinoglu, N. Rulkov, R. Huerta, Information-theoretic optimization of chemical sensors, Sens. Actuator B-Chem., 148 (2010) 298-306. [18] A. Kolmakov, X.H. Chen, M. Moskovits, Functionalizing nanowires with catalytic nanoparticles for gas sensing application, J. Nanosci. Nanotechnol., 8 (2008) 111-121. [19] M. Stankova, X. Vilanova, J. Calderer, E. Llobet, J. Brezmes, I. Gràcia, C. Cané, X. Correig, Sensitivity and selectivity improvement of $\mathrm{rf}$ sputtered $\mathrm{WO}_{3}$ microhotplate gas sensors, Sens. Actuator B-Chem., 113 (2006) 241-248.

[20] W.B. Cross, I.P. Parkin, S.A. O'Neill, P.A. Williams, M.F. Mahon, K.C. Molloy, Tungsten oxide coatings from the aerosol-assisted chemical vapor deposition of $\mathrm{W}(\mathrm{OAr})_{6}$ ( $\left.\mathrm{Ar}=\mathrm{C}_{6} \mathrm{H}_{5}, \mathrm{C}_{6} \mathrm{H}_{4} \mathrm{~F}-4, \mathrm{C}_{6} \mathrm{H}_{3} \mathrm{~F}_{2}-3,4\right)$; photocatalytically active gamma- $\mathrm{WO}_{3}$ films, Chem. Mater., 15 (2003) 2786-2796.

[21] P. Ivanov, J. Hubalek, K. Malysz, J. Prásek, X. Vilanova, E. Llobet, X. Correig, A route toward more selective and less humidity sensitive screen-printed $\mathrm{SnO}_{2}$ and $\mathrm{WO}_{3}$ gas sensitive layers, Sens. Actuator B-Chem., 100 (2004) 221-227.

[22] S. Vallejos, V. Khatko, J. Calderer, I. Gracia, C. Canè, E. Llobet, X. Correig, Micromachined $\mathrm{WO}_{3}$-based sensors selective to oxidizing gases, Sensors and Actuators B: Chemical, 132 (2008) 209-215.

[23] Y. Liu, M. Liu, Growth of aligned square-shaped $\mathrm{SnO}_{2}$ tube arrays, Adv. Funct. Mater., 15 (2005) 57-62.

[24] B. Deb, S. Desai, G.U. Sumanasekera, M.K. Sunkara, Gas sensing behaviour of matlike networked tungsten oxide nanowire thin films, Nanotechnology, 18 (2007) 7. [25] Y. Wu, Z. Xi, G. Zhang, J. Yu, D. Guo, Growth of hexagonal tungsten trioxide tubes, J. Cryst. Growth, 292 (2006) 143-148.

[26] Q. Xiang, G.F. Meng, H.B. Zhao, Y. Zhang, H. Li, W.J. Ma, J.Q. Xu, Au nanoparticle modified $\mathrm{WO}_{3}$ nanorods with their enhanced properties for photocatalysis and gas sensing, J. Phys. Chem. C, 114 (2010) 2049-2055. 
[27] F. Amano, D. Li, B. Ohtani, Fabrication and photoelectrochemical property of tungsten(VI) oxide films with a flake-wall structure, Chem. Comm., 46 (2010) 2769-2771. [28] S. Vallejos, T. Stoycheva, P. Umek, C. Navio, R. Snyders, C. Bittencourt, E. Llobet, B. Blackman, S. Moniz, X. Correig, Au nanoparticle-functionalised $\mathrm{WO}_{3}$ nanoneedles and their application in high sensitivity gas sensor devices, Chem. Commun., 47 (2011) 565 567.

[29] H. Xia, Y. Wang, F. Kong, S. Wang, B. Zhu, X. Guo, J. Zhang, Y. Wang, S. Wu, Audoped $\mathrm{WO}_{3}$-based sensor for $\mathrm{NO}_{2}$ detection at low operating temperature, Sens. Actuator B-Chem., 134 (2008) 133-139.

[30] S. Ashraf, C.S. Blackman, R.G. Palgrave, I.P. Parkin, Aerosol-assisted chemical vapour deposition of $\mathrm{WO}_{3}$ films using polyoxometallate precursors and their gas sensing properties, J. Mater. Chem., 17 (2007) 1063-1070.

[31] V. Khatko, S. Vallejos, J. Calderer, I. Gracia, C. Cané, E. Llobet, X. Correig, Micromachined $\mathrm{WO}_{3}$-based sensors with improved characteristics, Sens. Actuator B-Chem., 140 (2009) 356-362.

[32] Y.J. Choi, I.S. Hwang, J.G. Park, K.J. Choi, J.H. Park, J.H. Lee, Novel fabrication of an $\mathrm{SnO}_{2}$ nanowire gas sensor with high sensitivity, Nanotechnology, 19 (2008) 4.

[33] N.M. Shaalan, T. Yamazaki, T. Kikuta, Effect of micro-electrode geometry on $\mathrm{NO}_{2}$ gas-sensing characterisitics of one-dimensional tin dioxide nanostructure microsensors Sens. Actuator B-Chem., 156 (2011) 784-790.

[34] A. Labidi, C. Jacolin, M. Bendahan, A. Abdelghani, G. J., K. Aguir, M. Maaref, Impedance spectroscopy on $\mathrm{WO}_{3}$ gas sensor, Sens. Actuator B-Chem., 106 (2005) 713718.

[35] S.R. Morrison, Chemical Sensors, in: M. Sze (Ed.) Semiconductor Sensors, Jhon Wiley \& Sons, Inc., 1994.

[36] B. Roldan Cuenya, Synthesis and catalytic properties of metal nanoparticles: Size, shape, support, composition, and oxidation state effects, Thin Solid Films 518 (2010) 3127-3150.

[37] A. Gurlo, N. Barsan, A. Oprea, M. Sahm, T. Sahm, U. Weimar, An n- to p-type conductivity transition induced by oxygen adsorption on alpha- $\mathrm{Fe}_{2} \mathrm{O}_{3}, \mathrm{Appl}$. Phys. Lett., 85 (2004) 2280-2282.

[38] Y.S. Kim, S.C. Ha, K. Kim, H. Yang, S.Y. Choi, Y.T. Kim, J.T. Park, C.H. Lee, J. Choi, J. Paek, K. Lee, Room-temperature semiconductor gas sensor based on 
nonstoichiometric tungsten oxide nanorod film, Appl. Phys. Lett., 86 (2005) 213105213101-213103.

[39] T. Siciliano, A. Tepore, G. Micocci, A. Genga, M. Siciliano, E. Filippo, Transition from n- to p-type electrical conductivity induced by ethanol adsorption on alpha-tellurium dioxide nanowires, Sens. Actuator B-Chem., 138 (2009) 207-213.

[40] T. Wolkenstein, Electronic Processes on Semiconductor surfaces during Chemisorption, Consultants Bureau, New York, 1991. 


\section{Biographies}

T. Stoycheva graduated in engineering physics from the Sofia University "St. Kliment Ohridski", Sofia, Bulgaria in 2006. Now she is a PhD student in the Electronic Engineering Department at the Universitat Rovira i Virgili, Spain. Her research interests include fabrication and study of nanostructured chemical sensors by chemical vapor deposition techniques and characterization of metal-oxide gas sensors.

S. Vallejos received her $\mathrm{PhD}$ degree in Electronics at Universitat Rovira i Virgili and is currently a Postdoc at University College London. At present she is interested in the development and application of functional nanostructured semiconducting materials for gas sensing applications.

C. Blackman is a lecturer at University College London and is interested in functional material synthesis for application in fields relevant to the green agenda; health, environment and energy. He has pioneered the use of advanced methods for the production of functional materials and his current research is generally focussed in the area of "Green nanotechnology", the application of green chemistry principles to the design of nanoscale products, the development of nanomaterial production methods and to the application of nanomaterials. His current experimental interests are at the forefront of nanoparticle research and involve the synthesis of nanostructured semiconducting materials with incorporation of metal nanoparticles and the application of these functionalized materials in various fields including environmental monitoring, photovoltaic devices and catalysis.

S. J. A. Moniz received his MSci degree in Chemistry at UCL and is currently a PhD student working in the field of Inorganic and Materials Chemistry, also at UCL. He is primarily interested in the synthesis of single-source molecular precursors for growth of complex oxide films via CVD for use in computer memory applications and solar energy conversion.

J. Calderer received his degree in Physics in 1973 and the PhD in 1981 in the University of Barcelona. He has been working in technology and characterization of photovoltaic solar cells, heterojunction bipolar transistors and silicon-based integrated optical sensors. At present he is a staff member of the Department of Electronic Engineering (DEE) of the Polytechnic University of Catalonia (UPC, Barcelona). His main research activity focuses on resistive gas sensors using metal oxide compounds.

X. Correig was graduated in telecommunication engineering from the Universitat Politècnica de Catalunya (UPC), (Barcelona, Spain) in 1984, and received his PhD in 1988 from the same university. He is a full professor of Electronic Technology in the Electronic Engineering Department at the Universitat Rovira i Virgili (Tarragona, Spain). His research interests include heterojunction semiconductor devices and solid-state gas sensors. 